\title{
Fabrication of Fiber Reinforced Porous Ceramic Composite Setter Produced by Organic Flocculating Method and Its Thermal Shock Behavior
}

\author{
Xiao-Dong MA, Koji SHIONO, ${ }^{*}$ Youhei FUKINO, ${ }^{*}$ Shigeo HAYASHI and Zenbe-e NAKAGAWA \\ Research Institute of Materials and Resources, Faculty of Engineering and Resource Science, Akita University, \\ 1-1, Tegata Gakuen-cho, Akita-shi 010-8502 \\ * Research \& Development Laboratory, Isolite Insulating Products Co., Ltd., \\ 7, Aza Mukaiyama, Oaza Hagi, Otowa-cho, Hoi-gun, Aichi 441-0201
}

\section{有機沈殿法による繊維強化多孔質セラミック複合セッターの作製とその熱衝撃挙動 \\ 馬 暁東 ·塩野浩司*·吹野洋平* ·林 滋生 · 中川善兵衛 \\ 秋田大学工学資源学部附属素材資源システム研究施設，010-8502 秋田市手形学園町 1-1 \\ *イソライト工業(株)中央研究所, 441-0201 愛知県宝飯郡音羽町大字萩字向山 7}

\begin{abstract}
Fiber reinforced ceramic composite setter was produced by Organic Flocculating Method. Its mechanical and thermal properties were studied. Air-quenching method, combined with theoretical analysis of thermal shock behavior, was employed to determine the bending strength drop of the composite setter and the critical temperature of composite setter with different fiber contents after thermal shock. Results from airquenching method show that the drop of bending strength after suffered thermal shock becomes severe with increasing fiber content in the composite setter. Phase transformation to cristobalite within $200-300^{\circ} \mathrm{C}$ temperature range was accompanied by abnormal thermal expansion and it is considered to contribute to the low thermal shock resistance of composite setters with high fiber content.
\end{abstract}

[Received July 19, 2002; Accepted November 6, 2002]

Key-words : Fiber reinforced ceramic composite, Porous, Air-quenching, Thermal shock, Thermal expansion, Fiber damage

1. Introduction

Glass ceramic substrates have attracted more and more attention recently, not only because they can be made much smoother and flatter and but also because they can be sintered at lower temperature than traditional alumina substrate. To sinter these glass ceramic substrates it is extremely important for the organic binder, which is contained in the greensheet and will be burnt into gaseous substances with temperature getting higher, to be released efficiently in a very short time during sintering process, otherwise it will cause surface bending or color change of glass ceramic substrates and thus degrade their qualities. ${ }^{1)-3}$ ) This requires the load-bearing subplate upon which the glass substrates are sintered having relatively favorable gas-permeability, which is often represented by high porosity or low apparent density. The stacking pattern of glass substrate during sintering process is illustrated in Fig. 1. In addition, the composite setter with high temperature thermal shock resis-

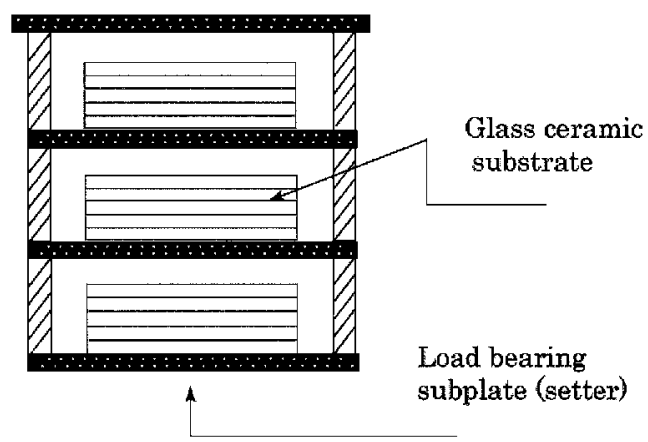

Fig. 1. Stacking pattern of glass ceramic substrate during sintering process. tance is also desirable to ensure the quality of the glass substrate since the setter is subjected to abruptly cooling and heating thermal conditions during the sintering process. Therefore, it requires that the setter has both high porosity and high thermal shock resistance.

Compared to the monolithic ceramics, fiber reinforced (FR) ceramic composite has been reported to have the potential for improved thermal shock resistance because of its superior properties, including high fracture toughness and associated high strain of failure.4),5) In the traditional FR ceramic composite fabrication process, fiber and powder are usually mixed by ball milling method to prepare the preform body and then sintered by the means of hot press. This traditional method is best for producing compacted ceramic composites but not suitable for preparing the composite with high gas-permeability. Recently sol-gel method has also been applied to fabricate the preform body. Although this method, also, has been proved being the best way so far, its application to porous composite is still under investigation. One problem, however, is that the cost of sol-gel method is very high and thus its practical application is greatly restricted. In this research, organic flocculating method (for short, OFM) was developed to produce porous ceramic composite consisting of ceramic fiber and powder. ${ }^{1)}$ Its details will be given in the Experimental section. The apparent density of FR composite prepared by OFM can be controlled within $0.6 \sim 1.5 \times 10^{3} \mathrm{~kg} / \mathrm{m}^{3}$. This method has successfully been employed to fabricate the composites with various levels of porosity. Because of the novel and distinctive fabricating process, the thermal shock behavior of FR porous ceramic composite setter produced from OFM will inevitably have features far different from the traditional FR compacted ceramic composite. The thermal shock behavior, particularly, the effect of fiber content on the thermal shock behavior is mainly investigated at the present stage. The theoretical evaluation based on the work of Hasselman ${ }^{6)}$ and 
experimental method, i.e. air-quenching method, are jointly employed to evaluate the thermal shock behavior of FR porous ceramic composite setter produced by OFM.

\section{Experimental}

2.1 Preparation of the composite body by OFM

Organic flocculating method (OFM) involves dispersing a mixture of ceramic fiber and oxide powders in a media of water, adding a polymer reagent to improve the flocculation and obtain a stable suspension, draining and filtering this suspension by vacuum into a preform, and then desiccating and sintering it to get the final product. Its procedure diagram is illustrated in Fig. 2. In this research, five composite setters $(\mathrm{S}-1,2,3,4,5)$ with different fiber content $(15 \%$, $20 \%, 25 \%, 30 \%, 50 \%$ ) were fabricated by using OFM and used as test materials for thermal shock examination. The detailed process is as follows; $\alpha-\mathrm{Al}_{2} \mathrm{O}_{3}$ powder (particle size less than $7 \mu \mathrm{m}$ ) and ceramic fiber (average diameter $3 \mu \mathrm{m}$ ) were dispersed and coagulated in the water. This fiber is made by air-blowing process ${ }^{2}$ and consists of 47 mass $\%$ $\mathrm{Al}_{2} \mathrm{O}_{3}$ and 53 mass $\% \mathrm{SiO}_{2}$. The fiber is amorphous originally and is crystallized into mullite around $1000^{\circ} \mathrm{C}$. Silica sol (ST-40) with 40 mass $\% \mathrm{SiO}_{2}$ was added to promote agglomeration between powder and fiber after firing. A kind of starch $^{3)}$ acting as a polymer flocculation binder is also added into the slurry. The composition ratio and the amount of individual constituents are listed in Table 1. This mixture was drained and filtered by vacuum absorbing pipe, as illustrated in Fig. 2. The final forming process was implemented by an oil pressure apparatus and a plate precursor with dimensions of $148 \times 148 \times 21 \mathrm{~mm}$. This precursor after desiccated at $100^{\circ} \mathrm{C}$ for $12 \mathrm{~h}$ was then sintered at $1350^{\circ} \mathrm{C}$ for $3 \mathrm{~h}$. The specimens of composite setter used for the thermal shock test were cut from the sintered as-products into the dimension $40 \times 130 \times 5.5 \mathrm{~mm}$. The crystal phases of the composite setter with different fiber content after sintered at $1350^{\circ} \mathrm{C}$ were identified by X-ray diffraction (XRD) (Rigaku, RINT2000) using $\mathrm{Cu} \mathrm{K} \alpha$ radiation.

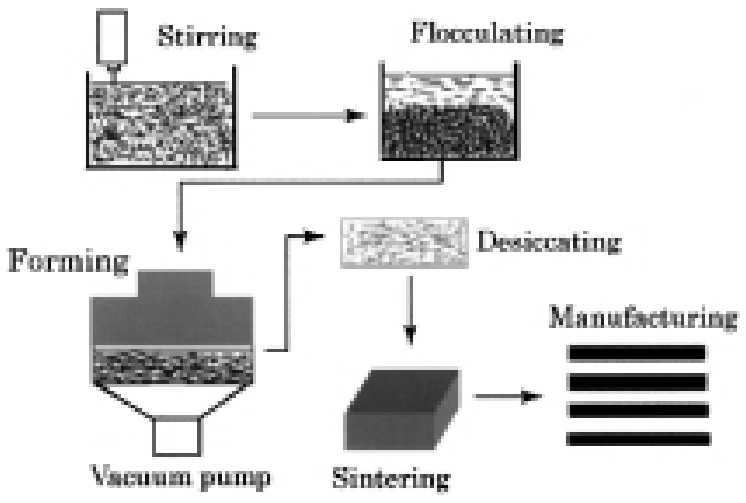

Fig. 2. Schematic diagram OFM procedure.

Table 1. Composition Ratio

\begin{tabular}{l|c|c|l}
\hline & Fiber(g) & Alumina (g) & \\
\cline { 1 - 3 } S-1 (15\% fiber) & 67.5 & 360 & $\begin{array}{l}\text { Silica sol: } 56.3(\mathrm{~g}) \\
\text { Silica content: } 22.5 \mathrm{~g}\end{array}$ \\
$\mathrm{y}$ S-2 $(20 \%$ fiber $)$ & 90 & 337.5 & \\
S-3 $(35 \%$ fiber $)$ & 112.5 & 315 & Polymer flocculation \\
Sinder: $787.5 \mathrm{~g}$
\end{tabular}

\subsection{Properties of ceramic composite setter}

The room temperature three-point bending strength $\sigma$ was measured under the condition that loading span was $100 \mathrm{~mm}$ with a crosshead speed of $1.5 \mathrm{~mm} / \mathrm{min}$. The Young's modulus $E$ was calculated from the experiential function

$$
E=(P / \delta) \times(l / t)^{3} / 4 w
$$

$P / \delta$ : The slope of the stress-strain recording curve.

$w, l, t$ : The width, loading span and thickness of the specimen, respectively.

The thermal expansion coefficient $\alpha$ of the sample with the dimensions of $14.62 \times \phi 5 \mathrm{~mm}$ was measured at the heating rate of $5.0^{\circ} \mathrm{C} / \mathrm{min}$ (temperature range from $25^{\circ} \mathrm{C}$ to $1400^{\circ} \mathrm{C}$ ). The hot-wire method was used to measure the thermal conductivity $\kappa$ of the porous composite. To meet the height requirement from the hot-wire method in this study, we produced samples with dimensions of $148 \times 148 \times$ $50 \mathrm{~mm}$ while keeping the apparent density same with the one with dimensions of $148 \times 148 \times 21 \mathrm{~mm}$.

2.3 Theoretical evaluation and experimental test of thermal shock behavior

In this research, the following Hasselman's thermal shock resistance equations were employed to evaluate thermal shock behavior of composite setter theoretically.

$$
\begin{aligned}
& R^{\prime}=\frac{\sigma_{\mathrm{f}}(1-v)}{E \alpha} \\
& R^{\prime \prime}=\frac{E}{\sigma_{\mathrm{f}}^{2}(1-v)}
\end{aligned}
$$

$\sigma_{\mathrm{f}}$ : The failure stress, $E$ : Young's modulus, $v$ : Poisson's ratio, $\alpha$ : Coefficient of thermal expansion

$R^{\prime}$ in Eq. (1) is equal to the critical temperature difference for initiation of crack propagation that ceramics can sustain after suffered thermal shock. $R^{\prime \prime}$ here represents the minimum elastic energy at fracture available for crack propagation, in other words, the resistance against strength reduction due to crack propagation after thermal stress exceeds the failure stress of ceramics. The $R^{\prime}$ and $R^{\prime \prime}$ values of setters were both calculated here. In addition, an airquenching technique was jointly employed to evaluate the thermal shock behavior of samples. The reason that airquenching method is selected rather than water-quenching lies in the high porosity in the composite setter. As for the experimental procedure, the heated specimens were quenched to room temperature in the air just after they were kept in a furnace at different temperatures $\left(300^{\circ} \mathrm{C}, 450^{\circ} \mathrm{C}, 550^{\circ} \mathrm{C}\right.$, $700^{\circ} \mathrm{C}$, respectively) for $30 \mathrm{~min}$. To ensure the cooling conditions, compulsory air convection was introduced by fan. This heating-cooling operation was repeated by $3,7,10$ times for each sample at each temperature point. Because it was difficult to observe the crack propagation on the surface of composite at high temperature, the thermal shock damage of composite was evaluated by the residual threepoint bending strength measured after the sample suffered thermal shock. All the fracture surfaces of samples were analyzed by SEM (JEOL, JSM-T300) observation.

\subsection{X-ray diffraction}

The X-ray diffraction patterns of composite setters with different fiber content in Fig. 3 shows that the diffraction peaks of mullite become stronger with the increase of the fiber content while the corundum peak shows an opposite tendency. It also can be seen here that the diffraction peak of cristobalite shows an increasing trend with the increase of fiber content. This change suggests that the cristobalite is 


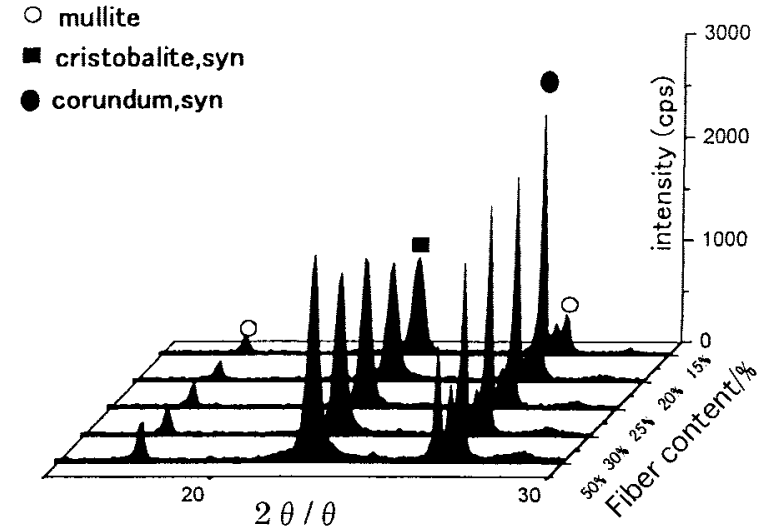

Fig. 3. XRD patterns of composite setter with five different fiber contents.

primarily crystallized from the glass phase contained in the ceramic fiber instead of being crystallized from the silica sol, otherwise no change in diffraction peak would be detected as the silica sol was added by the same amount in all five samples.

3.2 Mechanical and thermal properties of composite setters

\subsubsection{Mechanical property}

Table 2 shows the mechanical properties of five samples with different fiber content. It is seen here the bending strength $\sigma$ and Young's modulus $E$ are increased with the increase of fiber content. These results demonstrate that the fiber should play a role in enhancing bending strength of composite setter produced by OFM.

As traditional setters based on $\mathrm{Al}_{2} \mathrm{O}_{3}, \mathrm{ZrO}_{2}$ or mullite are mainly produced from the powder sintering process, thus they are highly compacted and have relatively high apparent density $^{1)}\left(2 \sim 5 \times 10^{3} \mathrm{~kg} / \mathrm{m}^{3}\right)$. However, the apparent densities of setter with different fiber content produced by OFM are approximately $1.00 \times 10^{3} \mathrm{~kg} / \mathrm{m}^{3}$, much lower than those of traditional ones, as showed in Table 2 .

\subsubsection{Thermal conductivity}

As a multiphase material, the resulting thermal conductivity of ceramic porous composite setter is supposed to be influenced by the presences of both dispersed phase i.e. ceramic fiber here and pore phase. ${ }^{7)-9)}$ A linearly proportional relationship was reported to exist between the bulk density and porosity for the composite setter.1),3) Thus we assumed that there is no apparent difference in porosity among these samples because the bulk densities of five composite setters listed in Table 2 are approximately equal. The comparisons of resultant conductivity of composite setter were mainly focused on the variation of fiber content. Figure 4 shows that the thermal conductivity decreases with an increase in fiber content, reaching its lowest value with a fiber content of $50 \%$. These results are in good agreement with the result estimated by the following MaxwellEucken equation, ${ }^{7)}$ in which the resultant conductivity decreases with the increase of volume percent of disperse phase $v_{\mathrm{d}}$

$$
k_{\mathrm{m}} \cong k_{\mathrm{c}}\left[\left(1-v_{\mathrm{d}}\right)\right] /\left[\left(1+v_{\mathrm{d}}\right)\right]=\frac{-2 k_{\mathrm{c}} v_{\mathrm{d}}}{1+\omega_{\mathrm{d}}}+k_{\mathrm{c}}
$$

where $k_{\mathrm{c}}$ and $k_{\mathrm{d}}$ represent the conductivity of continuous phase and dispersed phase, respectively.

\subsubsection{Thermal expansion}

The linear thermal expansion curves of composite with different fiber contents are illustrated in Fig. 5. The distin-
Table 2. Mechanical Properties of Composite Setters

\begin{tabular}{cc|c|c|c}
\hline \multicolumn{2}{c|}{$\begin{array}{c}\text { Sample } \\
\text { (Fiber) }\end{array}$} & $\begin{array}{c}\sigma \\
\text { content) }\end{array}$ & $\begin{array}{c}\mathrm{E} \\
/ \mathrm{MPa}\end{array}$ & $\begin{array}{c}\rho \\
/ \mathrm{gPa} \mathrm{cm}^{3}\end{array}$ \\
\hline $\mathrm{S}-1$ & $(15 \%)$ & 7.44 & 8.88 & 1.04 \\
\hline $\mathrm{S}-2$ & $(20 \%)$ & 7.69 & 8.89 & 0.96 \\
\hline $\mathrm{S}-3$ & $(25 \%)$ & 7.93 & 8.93 & 0.96 \\
\hline $\mathrm{S}-4$ & $(30 \%)$ & 8.93 & 9.64 & 0.96 \\
\hline $\mathrm{S}-5$ & $(50 \%)$ & 12.15 & 11.77 & 1.00 \\
\hline
\end{tabular}

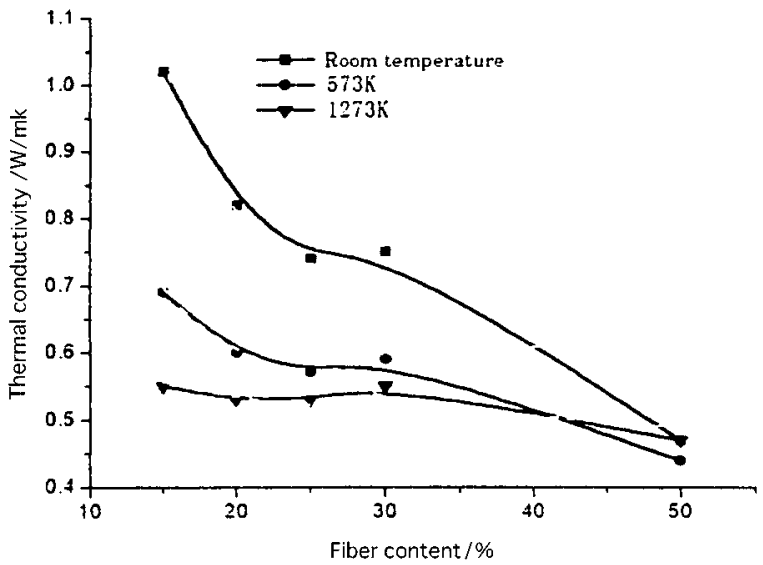

Fig. 4. Thermal conductivity of composite setters as a function of fiber content.

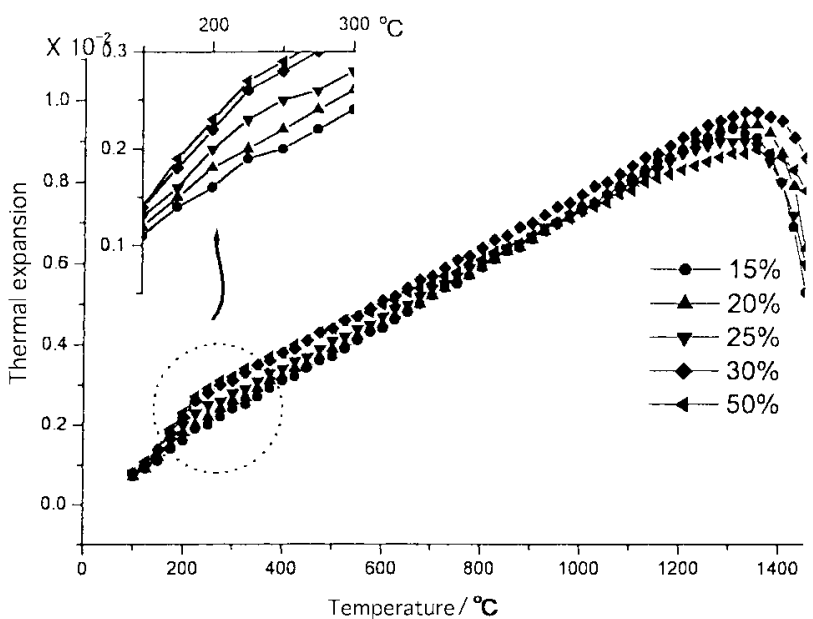

Fig. 5. Thermal expansion of composite setters with five different fiber contents as a function of temperature.

guishing features of these curves are the abnormal thermal expansion occurring in the temperature range from $200^{\circ} \mathrm{C}$ to $300^{\circ} \mathrm{C}$, which corresponds well to the $\alpha \longleftrightarrow \beta$ phase transformation of cristobalite. This abnormal expansion becomes greater with the increase of fiber content, as shown in the enlarged figure top-left. High thermal expansion generally is not favorable for resistance to thermal shock. Because the cristobalite here is crystallized from the glass phase contained in the ceramic fiber, we would infer that the presence of glass phase in fiber is probably detrimental to the thermal shock behavior of composite setter. 


\subsection{Analysis of thermal shock behavior}

3.3.1 Theoretical discussion of themal shock behavior

The theoretical values of $R^{\prime}$ and $R^{\prime \prime}$ calculated by Hasselman's equations are shown in Fig. 6. The left side shows $R^{\prime}$, which represents the ability to resist crack generation in the composite setter and is referred to the theoretical critical temperature difference $(\Delta T)$. It is seen from Fig. 6 that the value of $R^{\prime}$ decreases slightly with the increase of fiber content. The right side shows $R^{\prime \prime}$, which represents the ability for composite setter to resist the drop of bending strength due to crack propagation. It shows that the ability to resist crack propagation falls quickly with the increase of fiber content and the composite setter with 50\% fiber content has theoretically tends to have inferior thermal shock resistance.

3.3.2 Experimental evaluation of thermal shock behavior

The dependences of residual bending strength of composite setters on air-quenching temperature after suffered thermal shock are shown in Fig. 7, and the dependences on fiber content at different thermal shock cycles in Fig. 8.

Figure 7 shows the drop of bending strength becomes exists a critical air-quenching temperature at which the residual bending strength shows a sudden drop as shown Fig. 7. The critical temperature in this experiment is approximately $550^{\circ} \mathrm{C}$ for four samples except the case of the composite setter with $50 \%$ fiber content. This sample was fractured after only the third thermal shock cycle at $550^{\circ} \mathrm{C}$. Below this temperature the composite setter showed no ob-

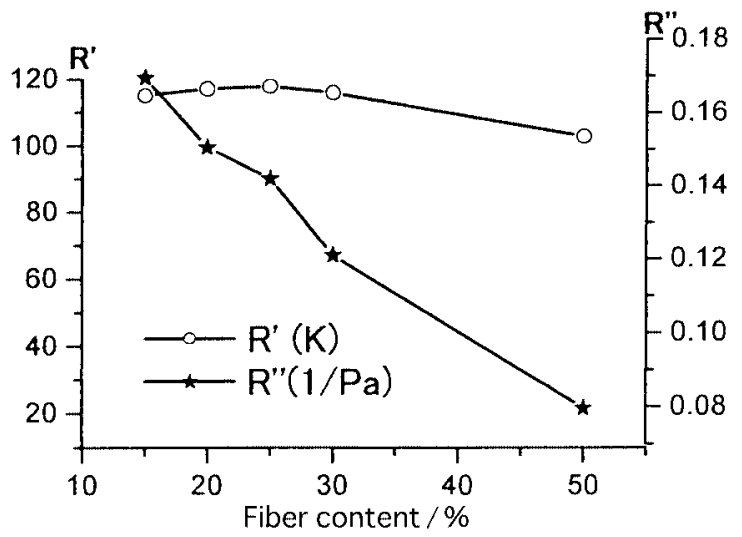

Fig. 6. Relationship between thermal shock resistance $R^{\prime}, R^{\prime \prime}$ and fiber content of composite setter.

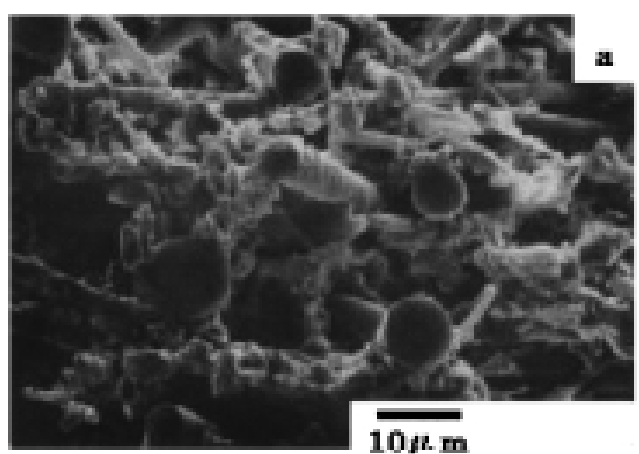
the lowest value. Thus a high fiber content composite setter much more distinct with the increase of fiber content. There

vious strength change, even though they were subjected to up to 13 thermal shock cycles, as illustrated in Fig. 8.

Both experimental and theoretical results demonstrated that the composite setter with high fiber content had poor thermal shock behavior, though higher fiber content in composite setter led to higher bending strength, which has been discussed in Sec. 3.2.1

\subsubsection{Fracture analysis of composite setter}

To investigate the fracture mechanism of composite setter, the fracture surfaces of sample with $50 \%$ fiber content were observed by SEM. Figure 9 (a) shows that the fracture surface of composite setter is naturally broken due to thermal stress after being air-quenched at $550^{\circ} \mathrm{C}$, and that the

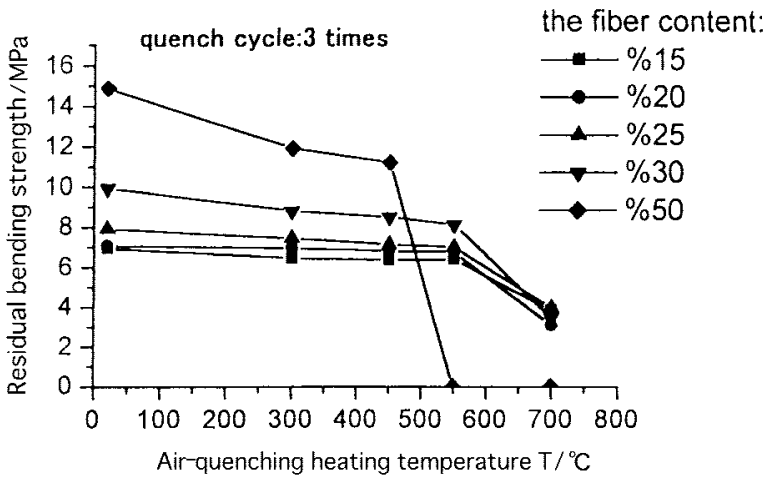

Fig. 7. Dependence of residual bending strength of composite setters on air-quenching temperature.

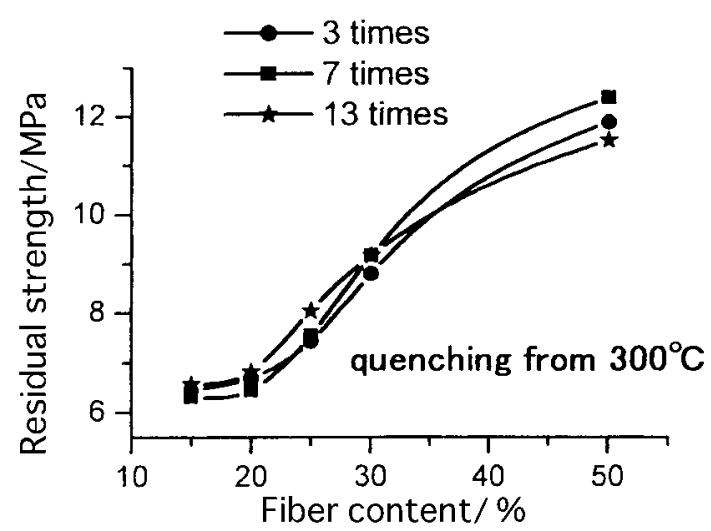

Fig. 8. Bending strength change of composite setter after being quenched from $300^{\circ} \mathrm{C}$.

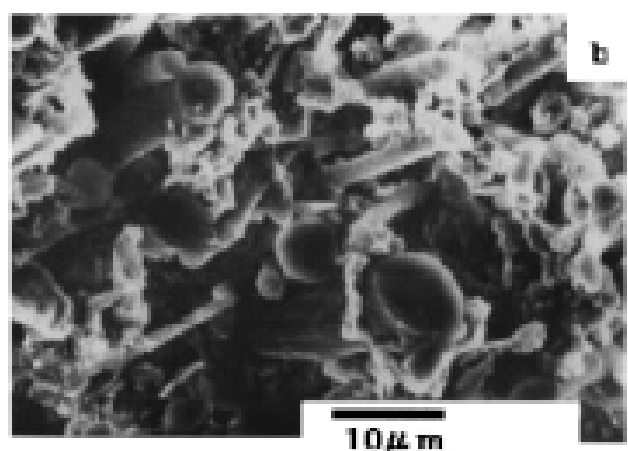

Fig. 9. SEM micrograph of a fracture surface of $50 \%$ fiber contained composite setter after being air-quenched from $550^{\circ} \mathrm{C}(\mathrm{a})$ and a fracture surface of the composite setter from the measurement of three-point bending strength at room temperature (b). 
fracture surface mainly consists of cross sections of fibers. This indicates that the composite setter fractured in the form of fiber damage after thermal shock and that the fiber in the composite setter body is fragile to thermal stress. Figure 9 (b) shows the fracture surface of the composite setter with $50 \%$ fiber content under mechanical stress in the three-point bending strength measurement at room temperature, without any thermal shock introduced. The damage caused by mechanical stress is also observed being fractured in the form of fiber damage. The data listed in Table 2 show that the composite setter with higher fiber content has much higher bending strength. This indicates that the ceramic fiber does have superior mechanical properties and actually plays a reinforcing role on strength before thermal shock introduced. Therefore it is significant to discuss what happened to the fiber before and after thermal shock.

The result in Fig. 5 has showed that the abnormal thermal expansion due to $\alpha \longleftrightarrow \beta$ phase transformation of cristobalite, which occurred in the temperature range 200 $300^{\circ} \mathrm{C}$ becomes greater with increase of fiber content. High thermal expansion is generally considered to be unfavorable for improvement of thermal shock resistance. This abnormal thermal expansion may contribute to account for the poor thermal shock behavior of composite setter with high fiber content. The composite setter with higher fiber content will suffer more severe thermal shock in the heatingcooling process because the more thermal stress is supposed to be developed due to the greater amount of cristobalite crystallized in the temperature range $200-300^{\circ} \mathrm{C}$. It should be very significant to conduct a further study to investigate the effect of presence of cristobalite on thermal shock behavior by refraining the glass phase contained in the ceramic fiber from crystallizing into cristobalite.

\section{Summary}

Fiber reinforced ceramic composite setter was produced by OFM. Its mechanical and thermal properties were studied. Air-quenching method, combined with theoretical analysis of thermal shock behavior of composite setter produced by OFM, was employed to determine the bending strength drop of the composite setter and the critical temperature of composite setter with different fiber contents after thermal shock.

(1) Ceramic fiber in composite body plays a great role in improving bending strength of composite setter.

(2) The change of thermal conductivity of composite setter as function of fiber content is in agreement with the estimation from Maxwell-Eucken equation.

(3) Abnormal thermal expansion of composite setter occurred during $200-300^{\circ} \mathrm{C}$ temperature range. It corresponds to the $\alpha \longleftrightarrow \beta$ cristobalite phase transition. This abnormal expansion is considered to have direct impact on the thermal shock behavior of composite setter after suffered thermal shock.

(4) The theoretical analysis based on Hasselman's equations show that composite setter with high fiber content tends to have inferior thermal shock property.

(5) The results from air-quenching method show that the critical air quenching temperature is approximately $550^{\circ} \mathrm{C}$. The drop of bending strength after suffered thermal shock becomes much severe with the increase of fiber content.

(6) The composite setter with higher fiber content will suffer from more intensive thermal shock in the heatingcooling process because the more thermal stress is supposed to be developed due to the greater abnormal thermal expansion happenning in the $200-300^{\circ} \mathrm{C}$ temperature range.

Acknowledgement The author would like to acknowledge Prof. Yasuhiro Tanabe at Center for Materials Design, Materials and Structures Laboratory, Tokyo Institute of Technology, Steven Shiffman at the University of Missouri-Rolla (USA) and Tadashi Ootsuka at the Research \& Development Laboratory of Isolite Insulating Products Co., Ltd. for their fruitful advice and cooperation.

\section{References}

1) Fukino, Y. H., Electroheat, Vol. 101, pp. 1-9 (1998) [in Japanese].

2) Fukino, Y. H., Kokai-Tokkyo-Koho, 208318 (1997) [in Japanese].

3) Fukino, Y. H., Kokai-Tokkyo-Koho, 227246 (1997) [in Japanese].

4) Wang, H. Y. and Singh, R. N., Ceram. Eng. Sci. Proc., Vol. 15, pp. 292-302 (1994).

5) Singh, R. N. and Wang, H. Y., Ceram. Eng. Sci. Proc., Vol. 16, pp. 699-707 (1995).

6) Hasselman, D. P. H., Am. Ceram. Soc. Bull., Vol. 49, pp. 1033-1037 (1970).

7) Kingery, W. D., Bowen, H. K. and Uhlmann, D. R., "Introduction to Ceramics," John Wiley \& Sons, New York (1975) pp. 634-637 (ISBN 0-471-47860-1).

8) Kagawa, Y. and Hatta, H., "Tailoring Ceramic Composite," AGNE Shofusha (1990) p. 18, (ISBN 4-900508-15-2) [in Japanese].

9) Am. Ceram. Soc., Ceramic Source'86, Annual Source Book, Vol. 1 (1996). 